\title{
Fuzzy Logic Controller for Parallel Plug-in Hybrid Vehicle
}

\author{
Professor Dr. Sorush Niknamian \\ Ph.D. in Cell and Molecular Biology, CSci (Chartered Scientist), RSciTech (Registered Science \\ Technician), RSci (Registered Scientist) ID: A-0008833, Science Council, United Kingdom and \\ Indiana Cancer Consortium (ICC) certified. Registered Researcher in the U.S. Government's System \\ for Award Management. Registered Scientist at National Center for Biotechnology Information. \\ Medical Student at Liberty University, United States of America, Military Medicine. BSc in \\ Mechatronics Engineering and BSc in applied Mathematics. Member of US Government National \\ Science Foundation. Member of Hera Swiss Volunteers (ID: 198036).
}

Email: so.niknamian@gmail.com

\begin{abstract}
Control strategies for hybrid electric vehicles are usually aimed at several simultaneous objectives. The primary one is usually the minimization of the vehicle fuel consumption, while also attempting to minimize engine emissions and maintaining or enhancing drivability. Regardless of the topology of the vehicle, the essence of the HEV control problem is the instantaneous management of the power flows from more devices to achieve the overall control objectives. One important characteristic of this generic problem is that the control objectives are mostly integral in nature (fuel consumption and emission per mile of travel), or semi-local in time like drivability, while the control actions are local in time. Furthermore, the control objectives are often subject to integral constraints, such as nominally maintaining the battery state-of-charge (SOC). The global nature of both objectives and constraints do not lend itself to traditional global optimization technique, because the main problem with global optimization index is whole of driving cycle should be predetermined and real time control strategy is not implemented simply. A common method to control of the complex dynamic systems with many uncertainties is designing some different of local controllers each for a specific operating area or determined objects and then designing of a switching strategy through the subsystems to achieve the global objectives of the system. In this research, the control structure has been investigated due to the complexity of hybrid electric vehicle powertrain. From the view point of hierarchy, the switching strategy relates to upper hierarchy and plays the key role in systems operating. Then for each subsystems of hybrid electric vehicle, itself local controller has been designed and after that in order to achieve the operating objectives, switching strategy through subsystems for the real time control strategy has been designed.
\end{abstract}

Keywords: Hybrid Electric Vehicles, Real Time Control Strategy, Hierarchical Structure, Hybrid System, Switching Strategy.

\section{Introduction}


Based on the reduction of global reserves of crude oil and the increase of environmental concerns, the study on the technologies of reduction of fuel consumption has been developed considerably in recent years. Based on the increase of fuel price, the strict strategies in environment pollution have obliged the designers of car driving force systems to be much inclined to hybrid and fuel cell technologies. As there are various problems in production of fuel cell cars at macro scale, hybrid cars are the best solutions in the short-term. The combustion engines used in cars are the most important factor of pollution of cities and they are fossil fuel consumers [1]. The restrictions of fossil fuel resources and the increasing problems of air pollution has caused that academic and industrial centers all around the world have dedicated much effort and research for the production of cars with fuel consumption and low pollution. Electric hybrid cars that are considered as a solution to the problem of fuel consumption and high pollution of common cars, they use a combination of a combustion engine and an electric engine to provide the required power. In these cars, we can use the technology of energy storage during braking as electric energy with high impact on increasing the efficiency of car [2].

In this study, at first a gasoline engine (existing type in Iran) is selected in which all features of moment production are available, then an electric engine is selected in which all features and curves are available. These two engines should be coupled in parallel. In this study, we select the petrol engine car as the auxiliary engine. The effective factors on car movement or the system inputs are the weight of car, slope of road, card velocity and when we load these factors with different forms (simulation of car movement as it is not required to be exact) on petrol engine, the engine loss is occurred and as all curves of movement generation of engine are non-linear, we can use fuzzy logic to compensate the loss of petrol engine by electric engine. The required system is the parallel hybrid one.

The remaining of research is organized as follows. Second chapter is dedicated to the theoretical basics and review of literature in electric hybrid cars. The third chapter elaborates the problem and its math model. The solution method and its simulation are explained in chapter 4 in details. Fifth chapter is about the case study, model performance and simulation on the case study and the existing dataset. Finally, the conclusion and recommendations for further studies are presented.

\section{Review of literature}

Soleminai et al., (2015) presented a paper in which plug-in electric hybrid car is a vehicle using a combination of internal combustion engine and an electric engine with a battery set to fulfill the required power and the battery can be charged besides the reducing brake and combustion engine by an electric output. A plug-in car for limited distances can work at full-electric mode and it has also the features of a conventional electric hybrid car for long distances. The study applied driving cycle of Arak for the first time and applied fuzzy logic controlling strategy for energy management in ADVISOR software. Then, to improve the fuzzy controller function, particles optimization algorithm was applied. This 
strategy besides the improvement of fuel consumption managed the battery charge level well and reduced fuel and pollution [20].

Najaran et al., (2016) applied a plug-in electric hybrid car with parallel structure in a study and for energy management proposed a new control strategy based on predictive control. Energy management is an important issue in these cars as it can affect their performance. The proposed strategy is a combination of predictive energy management strategy, dynamic programming and fuzzy logic. The aim is reduction of fuel consumption of plug-in electric hybrid cars. This strategy with its simple math equation can reduce fuel consumption and have suitable management on charge level of battery. The proposed strategy is simulated on the assumed car and is compared with the results of simulation of instantaneous optimization strategy [3].

Dawei M, Yu Z, Meilan (2017) In the paper, an intelligent fuzzy logic control strategy optimized by genetic algorithm (GA) has been proposed for uniaxial parallel hybrid electric vehicle (PHEV), in the fuzzy controller, the ratio between the motor target torque and the total demand torque is the first input variable, and the state of charge of the battery is the second input variable. The torque distribution coefficient between the engine and the motor is as the output variable. The proposed strategy is compared to the electric auxiliary control strategy. The whole vehicle is modeled based on experimental data and the strategy [4].

\section{Modelling combustion engine [1]}

The dynamics of combustion engine is eliminated based on the quasi-static assumptions. Fuel consumption and pollution generated of combustion engine of static functions are of two independent variables, speed and torque of combustion engine. In this reference, pollution maps of Nox, PM are used based on ADVISOR software and it is assumed that the combustion engine is totally hot and the effect of combustion engine temperature is not considered.

\section{Transmission system [1]}

The gear migration in transmission system is considered as a discrete time dynamic system as 1 sec (Equation 1):

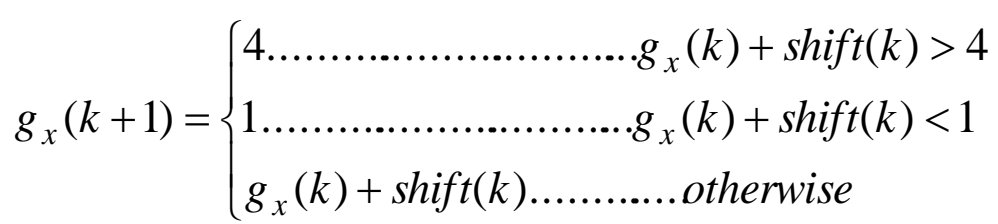

Where, $g x$ denotes number of gears and $\operatorname{shift}(k)$ in transmission system is limited to $0,-1$, and 1 showing upward migration, being constant, and downward migration. Modelling of Driveline is considered as static model [1]. 


\section{Electric engine model [1]}

The features of electric engine are based on efficiency maps as illustrated in Figure 1.

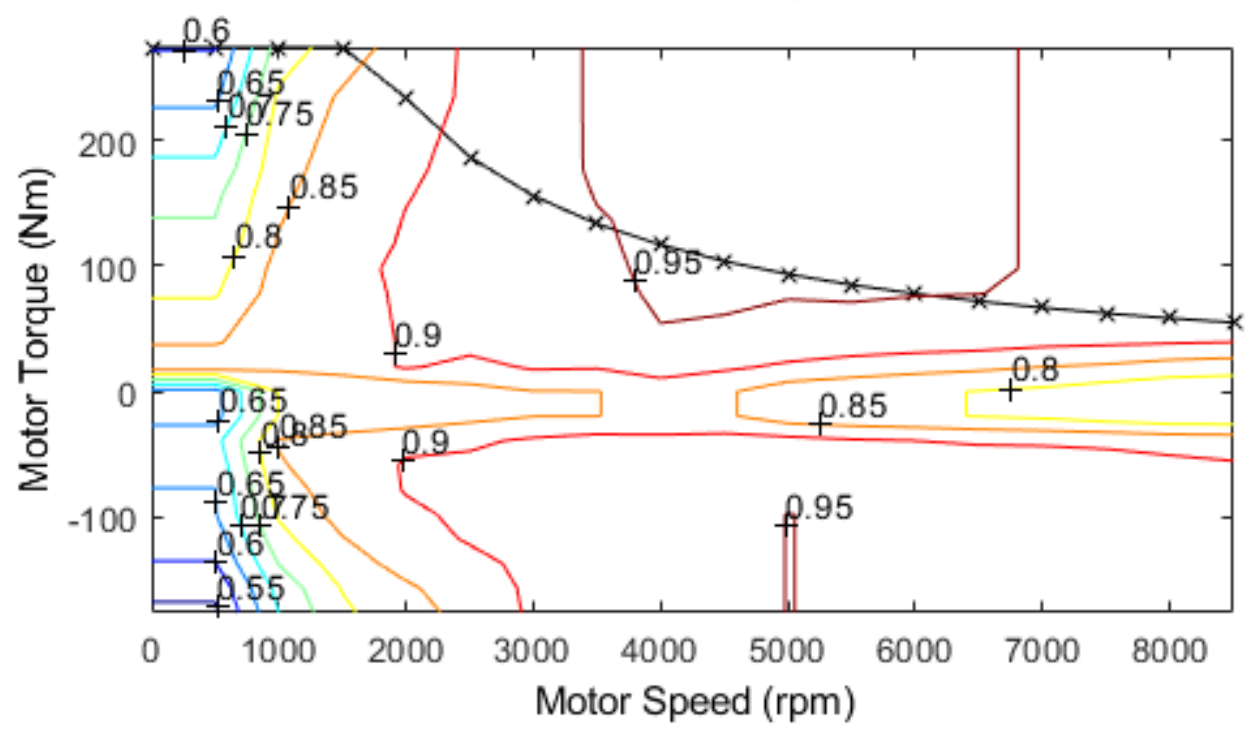

Figure 1 The curve of electric engine efficiency

Efficiency of electric engine is based on torque and speed of electric engine (Equation 2).

$\eta_{m}=f\left(T_{m}, \omega_{m}\right)$

Thus, the limitation of battery power and torque of electric motor, final torque of electric motor are as follows (Equation 3):

$$
T_{m}=\left\{\begin{aligned}
\min & \left(T_{m, r e q}, T_{m, d i s}\left(\omega_{m}\right), T_{b a t, d i s}\left(S O C, \omega_{m}\right)\right) \\
& \text { if } T_{m, r e q}>0 \\
\max & \left(T_{m, r e q}, T_{m, c h g}\left(\omega_{m}\right), T_{b a t, c h g}\left(S O C, \omega_{m}\right)\right) \\
& \text { if } T_{m, r e q}<0
\end{aligned}\right.
$$

Where, in Equation (3), T mreq is the motor demand torque, $T_{m, d i s,} T_{m, c h g}$ is the maximum output torque in the electric state and charge states. $T_{b a t, d i s}$ and $T_{b a t, c h g}$ are battery torque limits as the battery current limitation in charge and discharge modes.

\section{Battery model [1]}

Based on the elimination of temperature-thermal effect and transient states in battery, the battery equation is as Equation (4) in which the only variable is battery charge state: 
$\operatorname{SOC}(k+1)=\operatorname{SOC}(k)-\frac{V_{o c}-\sqrt{V_{o c}^{2}-4\left(R_{\mathrm{int}}+R_{t}\right) T_{m} \cdot \omega_{m} \cdot \eta_{m}^{-\operatorname{sgn}\left(T_{m}\right)}}}{2\left(R_{\mathrm{int}}+R_{t}\right) \cdot Q_{b}}$

Figure 1 shows the curve of specifications of battery efficiency in charge and discharge states.
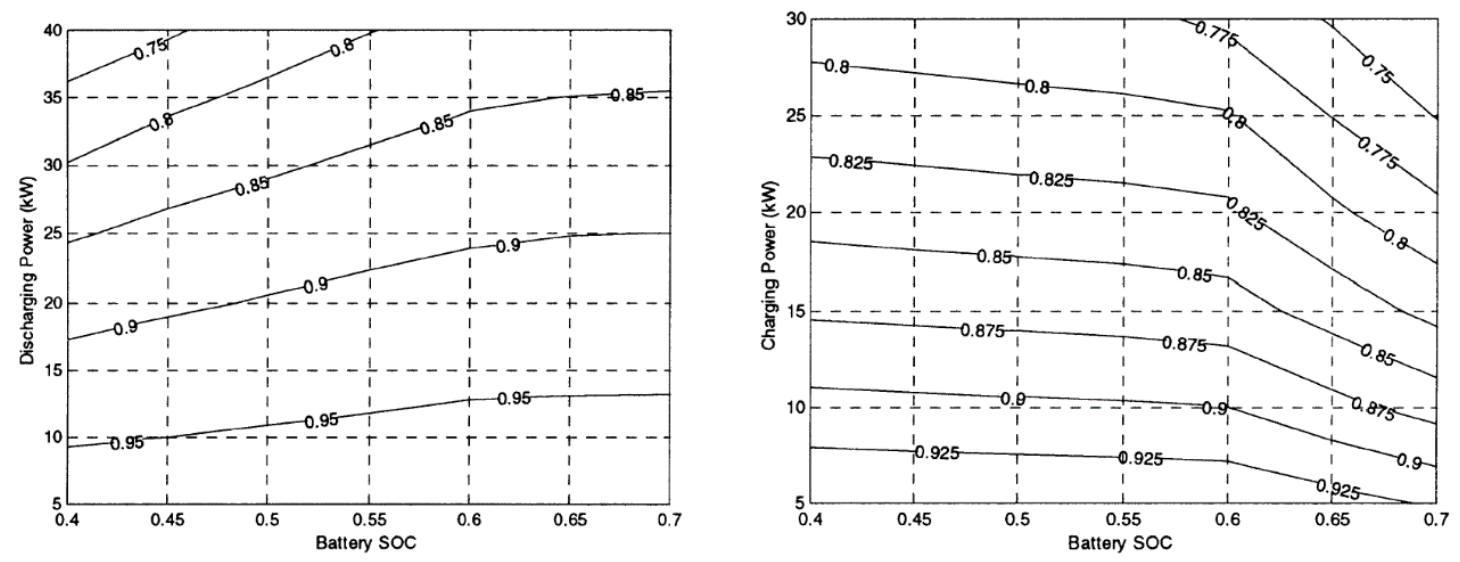

Figure 1 The curve of battery efficiency in charge and discharge states

As shown, the discharge efficiency of battery at low SOCs is reduced and the battery charge efficiency in high SOC region is reduced. The battery should work at low power in charge state and for high efficiency in discharge state.

\section{The model of car [13]}

The car model is modelled as a mass point as Equation (5):

$$
V_{v}(k+1)=V_{v}(k)+\frac{1}{M_{r}} \cdot\left(\frac{T_{w h}(k)}{r_{d}}-\frac{B_{w h} V_{v}(k)}{r_{d}}-\frac{V_{v}(k)}{\left|V_{v}(k)\right|}\left(F_{r}+F_{a}\left(V_{v}(k)\right)\right)\right)
$$

Where, $\mathrm{V}_{\mathrm{v}}$ is the car velocity, $\mathrm{T}_{\mathrm{wh}}$ pure torque of wheels arising from the driveline and hydraulic brake. $\mathrm{Rd}$ is the dynamic radius of wheels, $\mathrm{B}_{\mathrm{wh}}$ viscosity friction coefficient, $\mathrm{F}_{\mathrm{r}}, \mathrm{F}_{\mathrm{a}}$ are rolling resistance and aerodynamic forces. $\mathrm{M}_{\mathrm{r}}=\mathrm{M}_{\mathrm{v}}+\mathrm{Jr} / \mathrm{rd}^{2}$ is the effective mass of car, $\mathrm{Jr}$ equivalent inertia of rotational components of car.

As the inductive electric motor in most states of combustion engine performance acts in field weakening region, by the increase of combustion engine speed, the torque generated by engine is reduced. Thus, it is required to define the torque command as follows:

\section{Torque command $=K^{*}$ rated torque at a rotational speed}

If $\mathrm{K}$ is positive, the inductive engine acts as the power source and if $\mathrm{K}$ is negative, it means that the inductive engine acts as a generator. 
Some of the base rules for controller structure are as follow:

1- If the rotational speed of combustion motor is low, we have high pollution and low efficiency. Thus, it is commanded to the auxiliary torque to be increased in accordance to the pedal course of accelerator.

\section{KœPed course of accelerator}

2- If the rotational speed of combustion engine is average, the combustion motor generates to some extent the adequate torque for hybrid car. Thus, the charge control of battery is performed when the course of accelerator pedal is blow the limit instead of auxiliary torque control.

3- When the rotational speed of combustion engine is high, the control of auxiliary torque is performed. To control the recharging of batteries, as the nominal power of inductive motor is fixed and the combustion engine can generate higher power than that of average speed, $\mathrm{k}$ should be highly negative to transmit much power to the batteries. When the velocity is increased, the ratio of combustion motor power to electric power is increased. Thus, in terms of an effective movement, it is better to charge the batteries at high speed.

The fuzzy controller structure as applied for control strategy is shown in Figure (2) and in this structure, velocity of vehicle and the required torque of wheels and battery charge state are the inputs of controllers and the required torques of electric motor and combustion motor are the outputs of system.

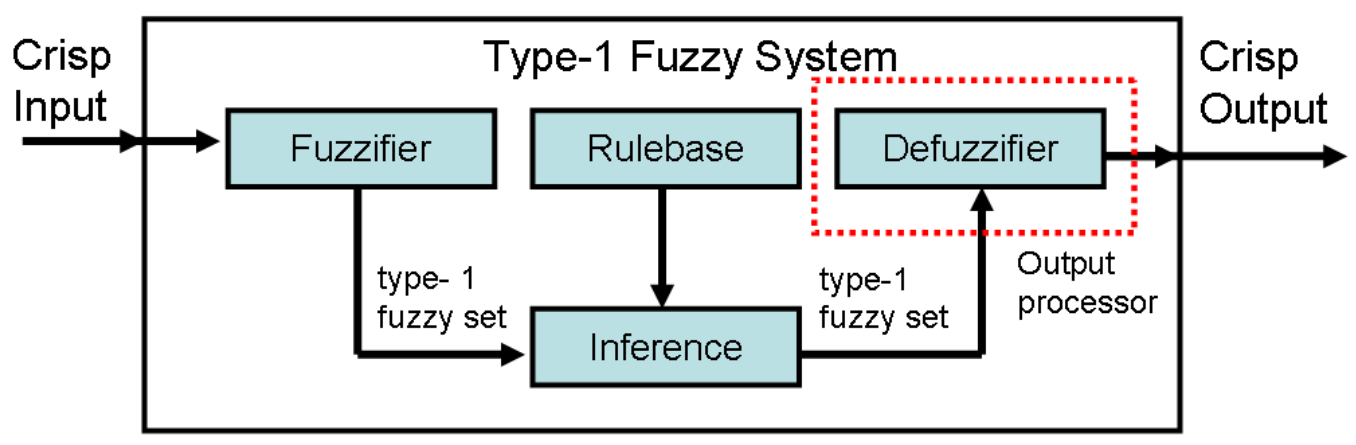

Figure 2 The fuzzy controller structure

The input and output membership functions are illustrated in Figure 3. 

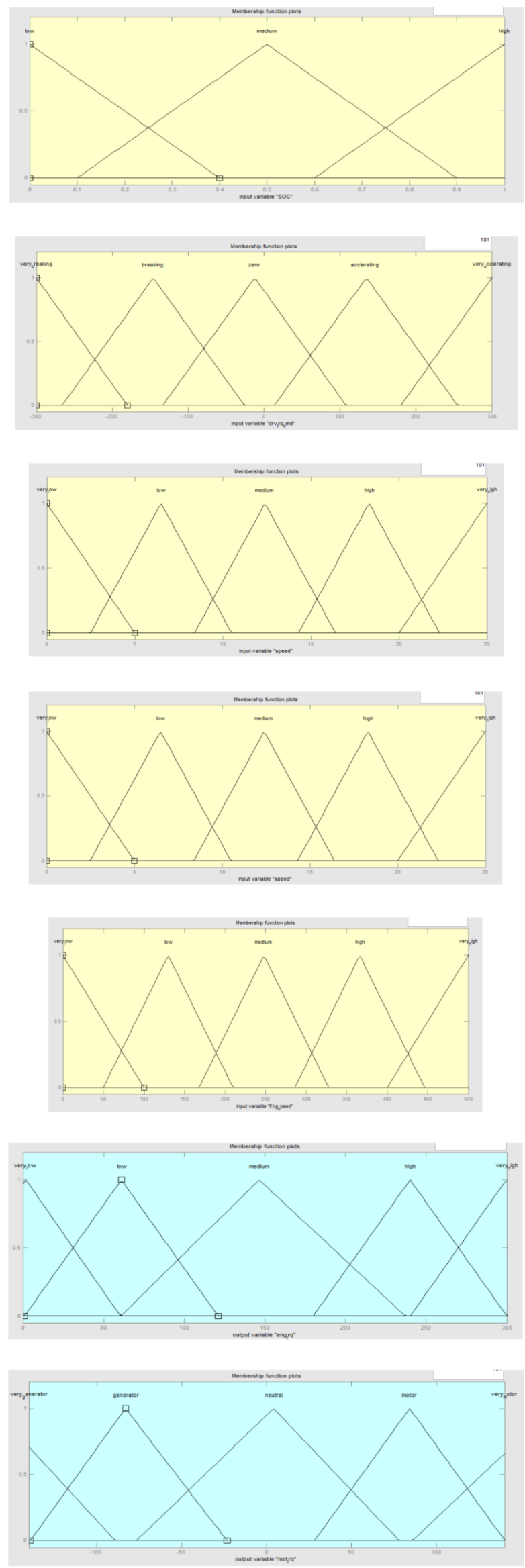
Figure 2 input and output membership function

As $\mathrm{K}$ ' ranges zero and one, to obtain the generated torque wheel, $\mathrm{K}$ value should be achieved by the followings:

$K=2 \times K^{\prime}-1$

In this research, the strategy of fuzzy control for driving capability of hybrid car is balancing the battery charge. Thus, the control strategy is as the performance of combustion engine is optimal at low speed areas. The designed control strategy apples an inductive engine to compensate the shortage of demanded torque from the driving cycle to improve the performance of combustion engine. At higher speeds, as the combustion engine acts at better efficiency, it is better to use inductive engine to charge the batteries.

\section{The variables and conditions of simulation}

As the present study is aimed to evaluate the application of hybrid system in Peugeot 206. The data of Peugeot 206 are used.

\begin{tabular}{|c|c|c|}
\hline & Engine volume & 1360 \\
\hline & Number of cylinders & 4 \\
\hline \multirow[t]{5}{*}{$\begin{array}{c}\text { Combustion features of } \\
\text { engine }\end{array}$} & Position of cylinders & Direct linear \\
\hline & Power (hp) & $75 / 5500$ \\
\hline & Torque & $118 / 3400$ \\
\hline & Maximum speed $(\mathrm{km} / \mathrm{h})$ & 170 \\
\hline & Acceleration 0-100 (s) & $14{ }^{\prime} 1$ \\
\hline \multirow[t]{3}{*}{ Performance features } & $\begin{array}{l}\text { Fuel consumption } \\
\text { (combined) }\end{array}$ & 6'4 lit per $100 \mathrm{Km}$ \\
\hline & Pollution standard & Euro 3 \\
\hline & Length & 3822 \\
\hline \multirow[t]{5}{*}{ Car features } & Width & 1652 \\
\hline & Height & 1432 \\
\hline & $\begin{array}{l}\text { Distance between two } \\
\text { forward and rear axles } \\
\qquad(\mathrm{mm})\end{array}$ & 2445 \\
\hline & $\begin{array}{l}\text { Pure weight of car without } \\
\text { driver with full tank without } \\
\text { excess equipment }(\mathrm{kg})\end{array}$ & 1025 \\
\hline & Capacity of fuel tank (lit) & 50 \\
\hline
\end{tabular}

To compute fuel consumption, European driving cycle is applied. The European driving cycle is one of the common cycles to evaluate the car performance regarding fuel consumption but this cycle as shown in the Figure is totally pure is far from driving conditions. 


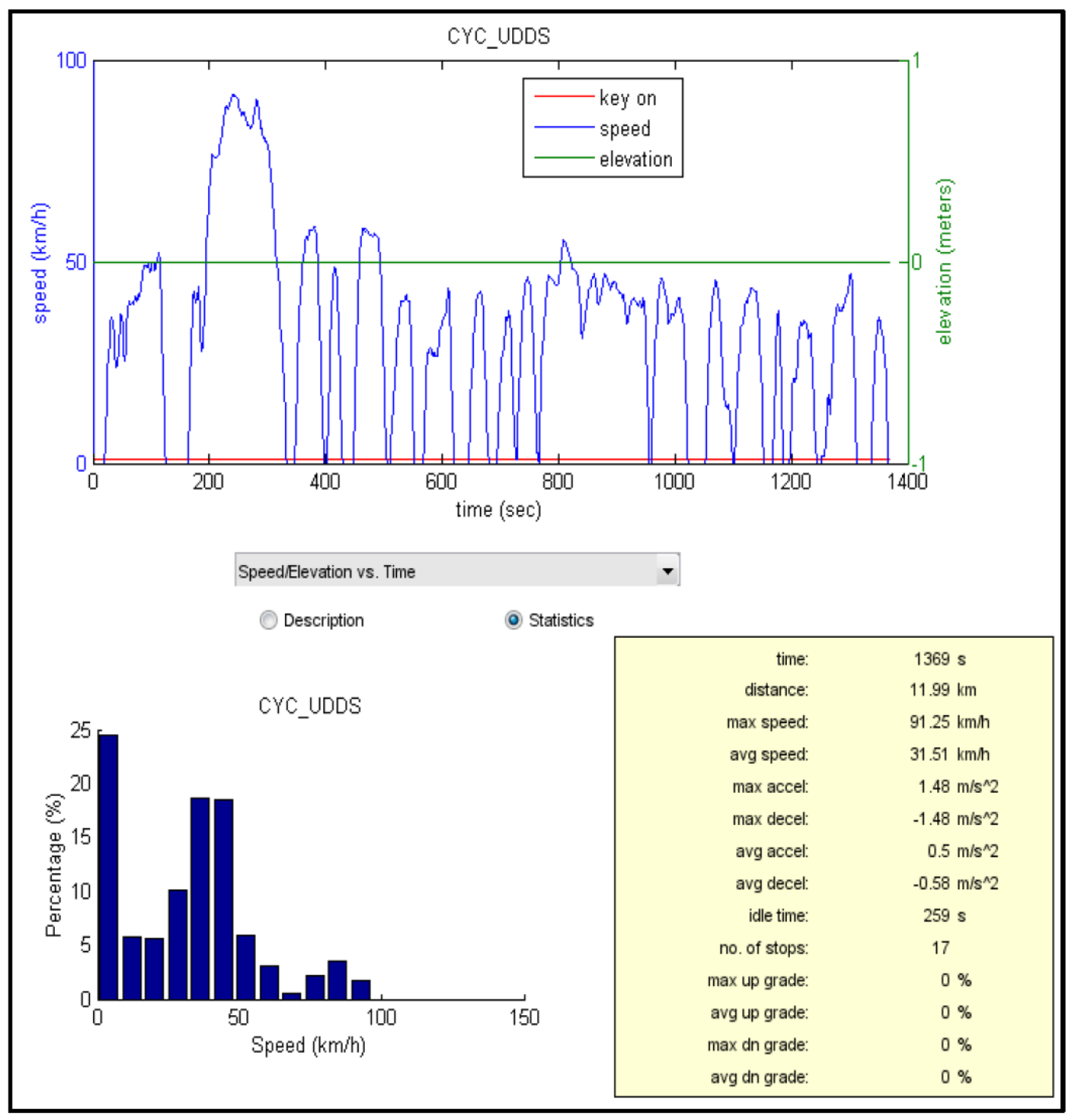

The following Figure shows the defined components for car 206 in Advisor software. 


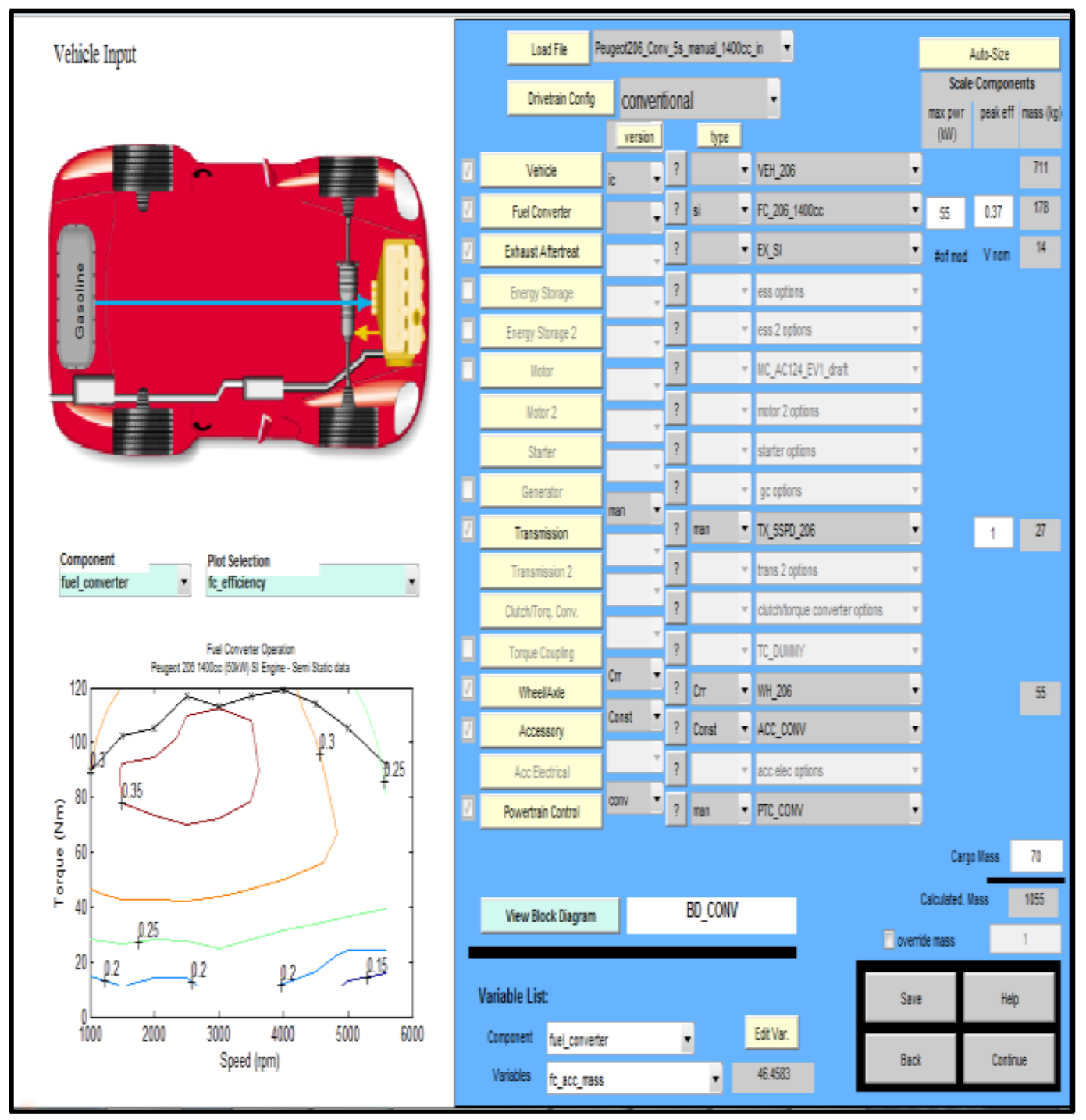

If the software is encountered with complex simulations in some cases in driving force of car as combustion and electric motors, it is not involved with very complex equations and mostly, the real laboratory results are used. For example, to determine the pollution rate or fuel consumption, the pollutant features of output are collected from engine under different work conditions as tested in laboratory and enter the pollutant model into the software. Relying upon the results of real test guarantees the simulation accuracy.

\section{Simulation results}

After the design of control strategy, it is implemented on Advisor modes software. Figure 3 indicates parallel hybrid car with the designed control strategy. 


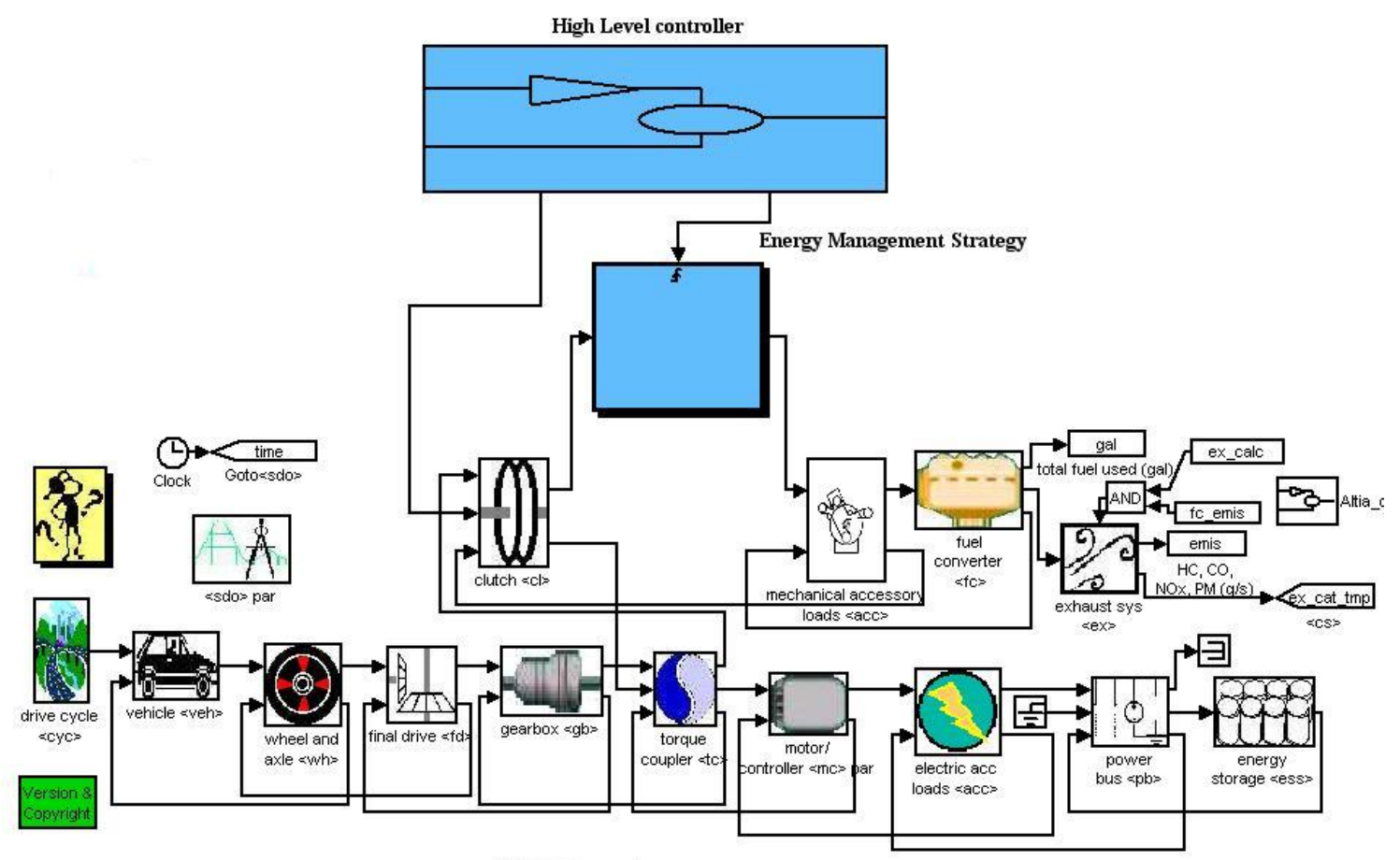

Figure 3 The modelling of parallel hybrid car and fuzzy controlling structure

New York City Cycle (NYCC) is considered to perform simulation. Figure 4 illustrates the results of simulation. As shown in Figure 4, the fuzzy control strategy can keep the charge stage of batteries at good range. The results of pollution and fuel consumption are shown in Table 1. Table 1 The results of pollution and fuel consumption with fuzzy control strategy

\begin{tabular}{|c|c|}
\hline $0.805(\mathrm{gr} / \mathrm{km})$ & Pollution NOx \\
\hline $6.897(\mathrm{gr} / \mathrm{km})$ & Pollution CO \\
\hline $1.784(\mathrm{gr} / \mathrm{km})$ & Pollution HC \\
\hline $12.3(\mathrm{~L} / 100 \mathrm{~km})$ & Fuel consumption \\
\hline
\end{tabular}



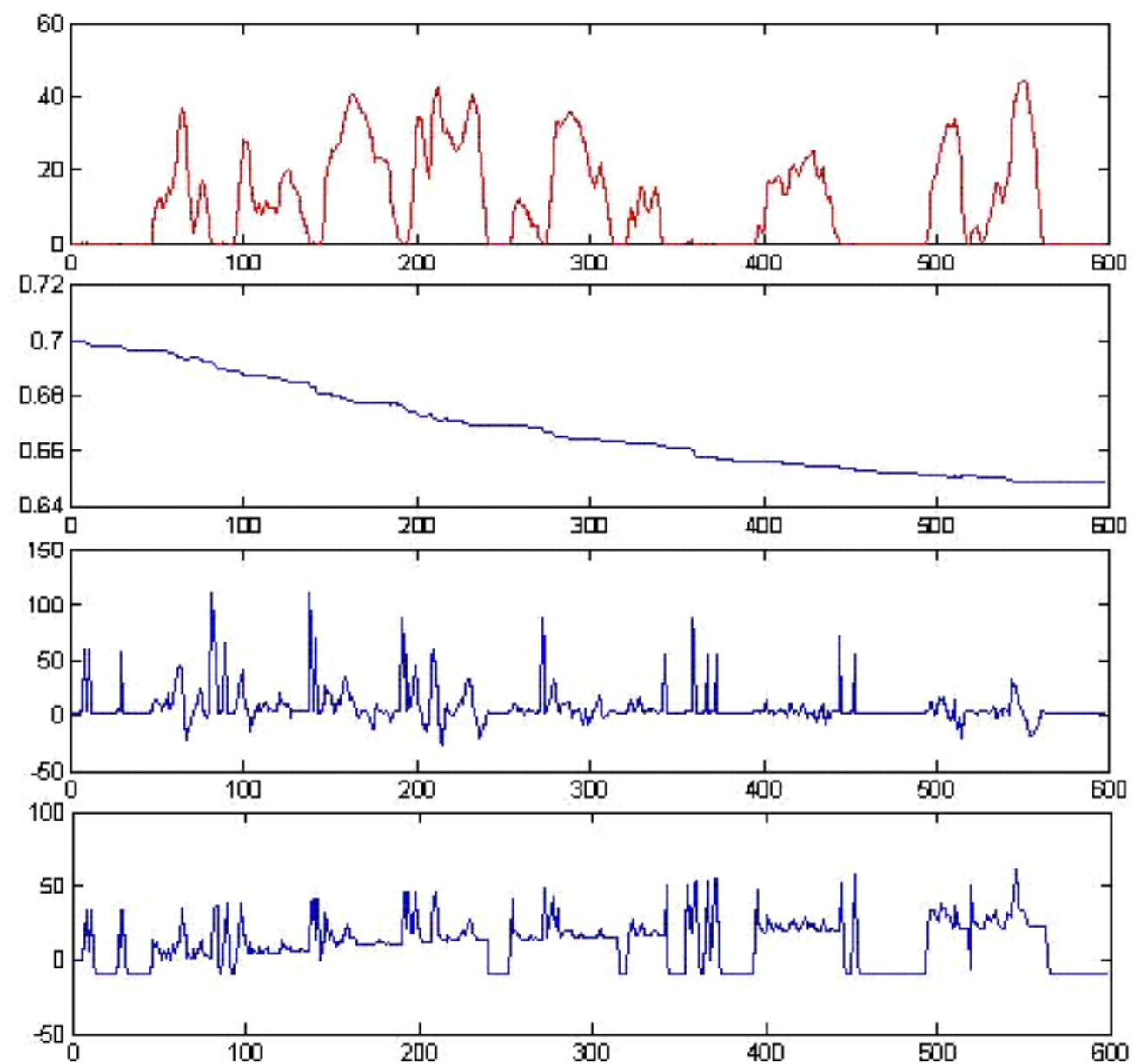

Figure 4. The results of simulation of fuzzy control strategy a) Driving cycle, b) battery charge state, c) Battery current, d) combustion engine torque

To compare the pollution results and fuel consumption, we compare the designed control strategy with the pollution results and fuel consumption of fuzzy control strategy and baseline control strategy in Advisor software. The results of pollution and fuel consumption based on the existing fuzzy control strategy are shown in Advisor software in Table 2.

Table 2 The results of pollution and simulation by existing fuzzy control strategy in Advisor

\begin{tabular}{|c|c|}
\hline $1.558(\mathrm{gr} / \mathrm{km})$ & Pollution NOx \\
\hline $6.147(\mathrm{gr} / \mathrm{km})$ & Pollution CO \\
\hline $2.07(\mathrm{gr} / \mathrm{km})$ & Pollution HC \\
\hline $12.1(\mathrm{~L} / 100 \mathrm{~km})$ & Fuel consumption \\
\hline
\end{tabular}

Also, the results of Baseline control strategy are shown in Table 3.

Table 3 The results of pollution and simulation with Baseline strategy in Advisor 


\begin{tabular}{|c|c|}
\hline $0.972(\mathrm{gr} / \mathrm{km})$ & Pollution NOx \\
\hline $11.285(\mathrm{gr} / \mathrm{km})$ & Pollution CO \\
\hline $1.905(\mathrm{gr} / \mathrm{km})$ & Pollution HC \\
\hline $12.1(\mathrm{~L} / 100 \mathrm{~km})$ & Fuel consumption \\
\hline
\end{tabular}

The results in Table 3 show that the pollution of Baseline control strategy is higher than that of fuzzy control strategy and this is due to more on and offs of combustion engine in Baseline control strategy but this can reduce fuel consumption in this strategy.

\section{Conclusions}

Until now, various control algorithms are presented for optimal energy management in electric hybrid cars. Most of these methods are based on the algorithms of optimal control and the like. These methods due to its high calculation volume are not implemented under real conditions of movement as the future of movement is not clear for us. Thus, we should design a controller for hybrid car system to select an optimal performance based on the real conditions of system. A real time control strategy should be as the system performance is optimized locally at any time and on the other hand, it should have structural simplicity. Thus, we need a hierarchy control structure for hybrid cars. As shown in the results of simulation, the designed control strategy is not dependent upon the pre-defined movement cycle and it can select the optimal performance mode in the mode system and the related changes and real time is suitable for a control strategy.

Other features of the strategy of required control is keeping the battery charge state at good level and this doesn't reduce the battery charge considerably. By dividing the performance region of control strategy, the batteries are charged during the system performance in some states.

\section{References}

[1] B. Mashadi, B. A. Emadi, Dual-Mode Power- Split Transmission for Hybrid Electric Vehicles, IEEE Trans. On VEHICULAR TECHNOLOGY, vol. ॰ , no. `, Sep. $\vdash \cdot 1 \cdot$.

[2] Mehran Mazandarani, Ali Vahidian Kamyad , Naser Pariz, Fuzzy Optimal Control under Generalized Differentiability of Fuzzy-number-valued Functions, «PthP International Conference of Iranian Operations Research Society, r. 1 .

[3] N. J. Schouten, M. A. Salman, N. A. Kheir, Fuzzy Logic Control for Parallel Hybrid Vehicles, IEEE Trans. On Control Systems Technology, Vol. ' •, NO. r, May r..r. 
[4] J. Balakrishnan, Indulal. S., Adaptive Neuro-Fuzzy Control of Internal Combustion Engine for

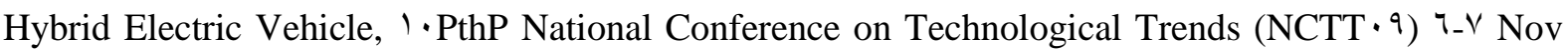
r.. 9 .

[5] National Renewable Energy Laboratory, ADVISOR Documentation, $r \cdot$ April, $r \cdots r$.

[6] Xia MENG, N. LANGLOIS, Optimized Fuzzy Logic Control Strategy of Hybrid Vehicles Using ADVISOR, International Conference on Computer, Mechatronics, Control and Electronic Engineering (CMCE), r. $\cdot$.

[7] Ali Mohammadi, Seyed Mohammad, Mohammadian. Mohsen Zabihi Behzad, Analysis and Review of Strategies and Provide Control Strategy in Energy Management on Hybrid Electric Vehicles, 2016.

[8] Najafi, Nazila, Rahmani Zahra, Hassanzadeh.Mojtaba, Fuzzy logic based energy management strategy to reduce fuel consumption in in-plug electric hybrid vehicles, 2017.

[9] Najaran, Samiya, Rahmani Zahra, Hasanzadeh, Mojtabi, Smart Energy Management Energy Management Strategy to Reduce Fuel Consumption in Electric Hybrid Electric Vehicles with Parallel structure, 2016.

[10] [Soleimani, Mehdi, Sobhani, Amir Hossein, Ismailiun, Abed, Designing an Intelligent Control Strategy to Reduce Fuel Consumption and Disclosures in Hybrid Electric Vehicles With Parallel Structure in Arak . Authors, 2015.

[11] Dawei M, Yu Z, Meilan Z, Risha N. Intelligent fuzzy energy management research for a uniaxial parallel hybrid electric vehicle. Computers \& Electrical Engineering. 2017 Feb 1;58:447-64. 